\title{
Geschichte der \\ neueren Philosophie \\ von Nikolaus von Kues bis zur Gegenwart
}

\author{
Im Grundriss dargestellt \\ von \\ Dr. Richard Falckenberg \\ ord. Professor zu Erlangen \\ Sechste verbesserte und ergänzte Auflage
}

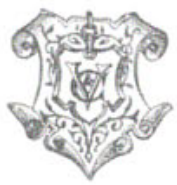

Leipzig

Verlag von Veit \& Comp.

1908 
Das Recht der Herausgabe von Übersetzungen vorbehalten.

Druck von August Prics in Leipzig. 
Den Herren Geh. Hofräten

Professor Dr. Rudolf Eucken in Jena

und

Professor Dr. Johannes Volkelt in Leipzig

in aufrichtiger Verehrung und herzlicher Dankbarkeit

gewiclmet 
